\title{
Interaction studies of Alzheimer's Cathepsin B protein with inhibitors in presence and absence of water
}

\author{
Nitin Chitranshi ${ }^{1,2^{*}}$, Pushpendra K Tripathi ${ }^{1}$, Prahlad K Seth ${ }^{2}$ \\ From 9th German Conference on Chemoinformatics \\ Fulda, Germany. 10-12 November 2013
}

\section{Background}

The accuracy of ligand-protein docking may be affected by the presence of water molecules on the surface of proteins. Water can form complex bridging networks and can play a critical role in dictating the binding mode of ligands. A recent analysis of high-resolution crystal structures of ligand-protein complexes revealed that $85 \%$ of the complexes had one or more water molecules bridging the interaction between ligand and protein. For predicting the binding modes and energies of protein-ligand interactions, molecular docking methods are commonly used. In order to obtain an accurate complex geometry and binding energy estimation, an appropriate method for calculating partial charges is essential. AutoDockTools software, widely used as interface for preparing input files, utilizes the either Gasteiger or Kollman partial charge calculation method for both protein and ligand charge calculations. However, it has already been reported that more accurate partial charge calculation and as a consequence, more accurate docking can be achieved by using quantum chemical methods. In common practice so far, the quantum chemical partial charges were applied to the ligands for docking calculations. The newly developed Mozyme function of MOPAC2009 allows fast partial charge calculation of proteins by quantum mechanical semiempirical methods. Thus, in the current study, we use the semi-empirical quantum-mechanical partial charge calculations to investigate the interaction energies and polarization effects of the various components of the binding pocket on a set of Cathepsin B protein.

\section{Results}

The docking accuracy was computed by using the original AutoDock scoring function with the set of 19 protein ligand complexes using Gasteiger, AM1 and PM3 partial charge calculation methods. This helped us to compare the effect of the partial charge calculation method on docking accuracy. It was seen that the docking accuracy in regard to complex geometry significantly increased when partial charges of the ligands and proteins were calculated with the semi-empirical PM3 method. Our results demonstrate that (i) the energetic of the key water molecule are more favorable for the binding site in the Cathepsin B protein (ii) Water bridging and triangle formation were seen between the key amino acid residue and the ligand (iii) The internal energy is significant factor for the binding modes of various ligands. It was also observed a statistically significant overall increase in accuracy when water molecules are included during docking simulations. Out of the 19 complexes analyzed in the course of our study, the geometry of 17 complexes were accurately calculated using PM3 partial charges, while the use of Gasteiger charges resulted in only 8 accurate geometries.

\section{Conclusion}

Our findings indicate that the inclusion of water molecules in ligand-protein docking results in significant increases in docking accuracy when the use of quantum chemical partial charge assignment on both ligand and proteins for predicting the docking simulations.

\footnotetext{
* Correspondence: nitinchitranshi@gmail.com

'Gautam Buddh Technical University, Lucknow 227202, Uttar Pradesh, India Full list of author information is available at the end of the article
} 


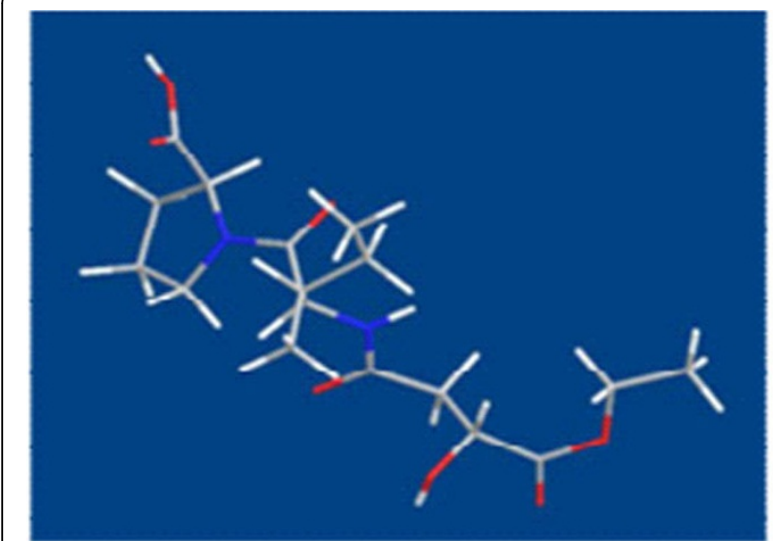

(a) EPO with AM1 Charges

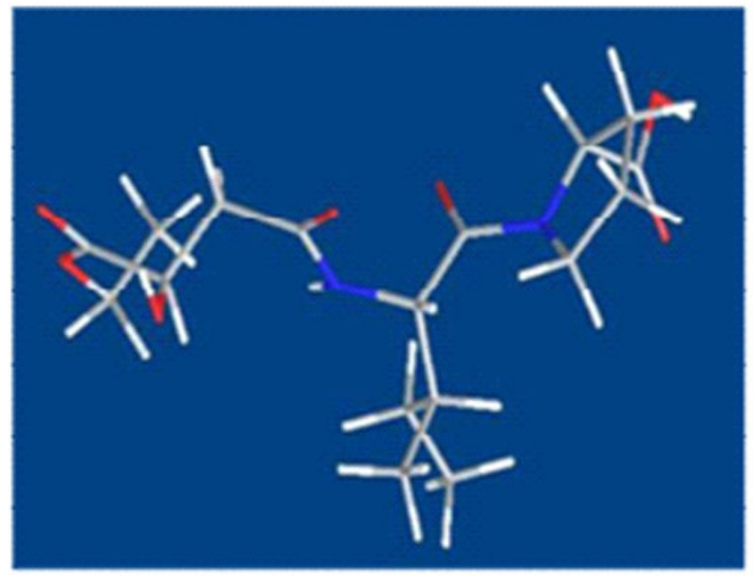

(c) EPO with PM3 Charges

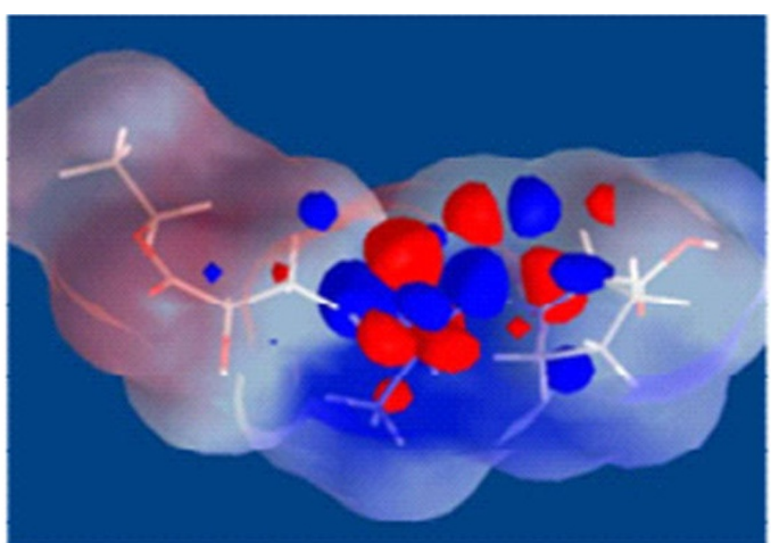

(b) EPO with Atst Charges HUнO surface

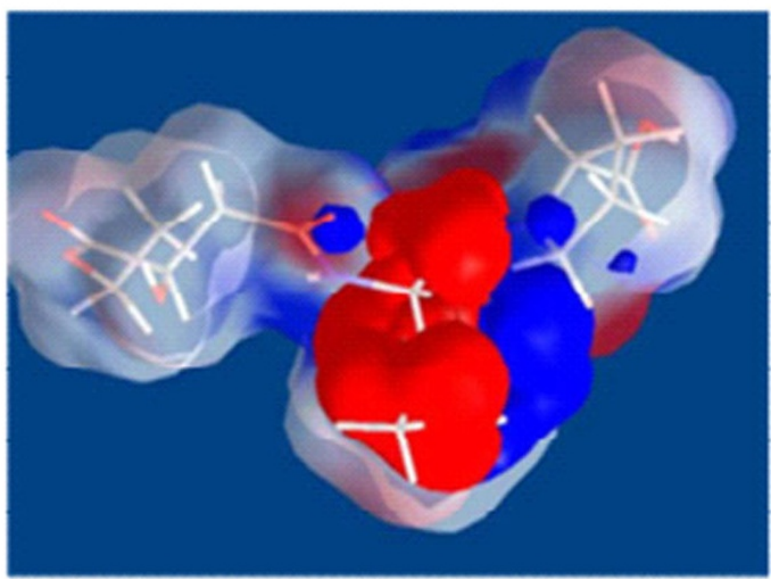

(d) EPO with PH3 Charges HUHO surface

Figure 1 Charge and force field applied to inhibitors for better docking score.

\section{Authors' details}

'Gautam Buddh Technical University, Lucknow 227202, Uttar Pradesh, India. ${ }^{2}$ Bioinformatics Centre, Biotech Park, Sector-G, Jankipuram, Lucknow 226021, Uttar Pradesh, India.

\section{Published: 11 March 2014}

\section{doi:10.1186/1758-2946-6-S1-P23}

Cite this article as: Chitranshi et al:: Interaction studies of Alzheimer's Cathepsin B protein with inhibitors in presence and absence of water. Journal of Cheminformatics 2014 6(Suppl 1):P23.
Publish with ChemistryCentral and every scientist can read your work free of charge

"Open access provides opportunities to our colleagues in other parts of the globe, by allowing anyone to view the content free of charge." W. Jeffery Hurst, The Hershey Company.

- available free of charge to the entire scientific community

- peer reviewed and published immediately upon acceptance

- cited in PubMed and archived on PubMed Central

- yours - you keep the copyright

Submit your manuscript here:

http://www.chemistrycentral.com/manuscript/
$(1$

Chemistry Central 